\title{
Übersicht
}

Manuel Müller*, Timo Müller*, Behrang Ashtari Talkhestani, Philipp Marks, Nasser Jazdi and Michael Weyrich

\section{Industrial autonomous systems: a survey on definitions, characteristics and abilities}

\author{
Industrielle autonome Systeme: ein Überblick über Definitionen, Merkmale und Fähigkeiten
}

https://doi.org/10.1515/auto-2020-0131

Received August 11, 2020; accepted November 25, 2020

\begin{abstract}
Autonomous systems are increasingly discussed in the domain of industrial automation. However, there is no consensus in the literature about the definition of industrial autonomous systems, what characteristics do they possess and how to distinguish them from intelligent industrial automation systems. Another important aspect is the comparison between the degree of automation and autonomy. Addressing this confusion, this paper starts with an analysis of the historical development of the term autonomy. Based on the similarities in the definitions, that were identified in a literature review, a comprehensive definition of industrial autonomous systems is presented, and four main characteristics of an industrial autonomous system are derived. Consequently, the characteristics for the realization of an industrial autonomous system (1) systematic process execution, (2) adaptability, (3) self-governance and (4) self-containedness are described in detail. Another objective of this contribution is to assist the developers of industrial autonomous systems to take the abovementioned characteristics into account. Furthermore, the developer is advised which abilities can be used to achieve the corresponding essential characteristics of industrial autonomous systems. To illustrate the characteristics and abilities of an industrial autonomous system, this paper gives a detailed description of three realized cases of application in industry.
\end{abstract}

*Corresponding authors with equal contribution: Manuel Müller, Timo Müller, Institute of Industrial Automation and Software Engineering, University of Stuttgart, Stuttgart, Germany, e-mails: manuel.mueller@ias.uni-stuttgart.de, timo.mueller@ias.uni-stuttgart.de

Behrang Ashtari Talkhestani, Philipp Marks, Nasser Jazdi, Michael Weyrich, Institute of Industrial Automation and Software Engineering, University of Stuttgart, Stuttgart, Germany, e-mails: behrang.ashtari@ias.uni-stuttgart.de, philipp.marks@ias.uni-stuttgart.de, nasser.jazdi@ias.uni-stuttgart.de, michael.weyrich@ias.uni-stuttgart.de
Keywords: autonomy, industrial autonomous systems, intelligent industrial automation systems, autonomous systems

Zusammenfassung: Autonome Systeme werden im Bereich der industriellen Automatisierung zunehmend diskutiert. Allerdings gibt es in der Literatur keinen Konsens über die Definition von industriellen autonomen Systemen, darüber, welche wesentlichen Merkmale sie besitzen und wie man sie von intelligenten industriellen $\mathrm{Au}$ tomatisierungssystemen abgrenzt. Ein weiterer wichtiger Aspekt ist der Unterschied zwischen dem Grad der Automatisierung und der Autonomie. Um dieser Verwirrung entgegenzuwirken, beginnt dieser Beitrag mit einer Analyse der historischen Entwicklung des Begriffs Autonomie. Ausgehend von den Ähnlichkeiten in bestehenden Definitionen, welche in einer Literaturrecherche identifiziert wurden, werden eine umfassende Definition von industriellen autonomen Systemen vorgestellt sowie vier Merkmale eines industriellen autonomen Systems abgeleitet. Anschließend werden die abgeleiteten Merkmale: (1) systematische Prozessausführung, (2) Anpassungsfähigkeit, (3) Selbstverwaltung und (4) Abgeschlossenheit, welche für die Realisierung eines industriellen autonomen Systems wesentlich sind, ausführlich beschrieben. Ein weiteres Ziel dieses Beitrags ist es, die Entwickler von industriellen autonomen Systemen bei der Umsetzung der oben genannten Merkmale zu unterstützen. Dazu werden die Entwickler beraten, welche Fähigkeiten dazu beitragen können, die entsprechenden wesentlichen Merkmale industrieller autonomer Systeme zu realisieren. Zur Veranschaulichung der Merkmale und Fähigkeiten eines industriellen autonomen Systems, wird eine detaillierte Beschreibung von drei realisierten industriellen Anwendungsfällen gegeben.

Schlagwörter: Autonomie, industrielle autonome Systeme, intelligente industrielle Automatisierungssysteme, autonome Systeme 


\section{Introduction}

Advances in the domain of industrial automation systems and artificial intelligence research have brought autonomous systems into the focus of industrial automation research. However, as Hrabia et al. state, there is no common understanding of what autonomous systems are and what characterizes them: "there is still a lack of a widely accepted concept of autonomous systems or robots that contains a detailed definition according to different aspects and a clear distinction to other system concepts" [1]. They conclude "the capability of adapting to the environment is strongly interconnected with autonomy"[1]. However, they do not derive a comprehensive definition. On the one hand, some systems are advertised as autonomous systems, although they are only highly automated systems. On the other hand, some autonomous systems are not labeled as such. In addition, a number of different properties have emerged that characterize an autonomous system as well as abilities attributed to autonomous systems. In order to provide a differentiated view on this topic, the relevant literature in the domain of industrial automation systems was investigated for this survey. The methodology of the investigation is described in Section 2. Starting with the historical development of the term autonomy, in Section 3, various definitions of autonomy are compared, and a summarizing definition is elaborated. From the definition in the narrow sense, the characteristics of industrial autonomous systems are derived (Section 3.1) and a distinction from intelligent industrial automation systems and classic automation systems is proposed (Section 3.2). Reviewing the abilities attributed to industrial autonomous systems in the literature, the abilities are categorized according to the characteristics (Section 4). In order to provide an example for the classification of systems as industrial autonomous systems based on the four derived characteristics, their manifestation is explored by three real-world examples (Section 5). Finally, Section 6 provides a conclusion and an outlook.

\section{Methodology}

Autonomous systems are of high research interest in different domains like aerospace, avionics, automotive and manufacturing etc. A search on Google Scholar, with the search terms "autonomic", "autonomous system", and "autonomy" resulted in more than 200,000 publications contributing to the topic of autonomous systems. In order to get a representative view on autonomous systems in industrial automation, the sorted by relevance-criterion of the Google Scholar search engine was used. Afterwards, it was sampled from the results and checked for the presence of the following: (1) a clear definition of an autonomous system (2) ascribed attributes, abilities or characteristics of autonomous systems (3) differentiations or a critical position towards the definition of autonomous systems and their characteristics. The focus was on the concept of autonomy rather than on methodologies for implementing autonomy. The investigation was proceeded until a set of at least 100 papers was investigated and in a set of 10 further papers no conceptually new aspects of autonomy were found. Using this policy, the investigation was stopped with about 200 contributions studied. Within this survey 50 of the investigated papers are cited.

Based on the contributions that provide a definition, a backward search was conducted to reveal the historical development of the term autonomy. Hence, the definitions of autonomy in the broad and the narrow sense are provided in the following section.

\section{Definitions of autonomy}

In this section, the historical development of the term $a u$ tonomy is shortly described in the context of industrial automation systems (Subsection 3.1). A more detailed description can be found in [2]. Subsequently, a definition of autonomy is synthesized from historical development and the more recent contributions from other authors. Furthermore, the distinction between autonomous systems, classic automation systems, and intelligent systems is discussed in Subsection 3.2.

\subsection{Historical development of the term autonomy}

Historically, the term autonomy is derived from the Greek terms autos and nomos, which means self-governing. Originally, the term was rather juridical-philosophical and denoted the right of an individual or a nation to make decisions and to organize itself independently without external interference [2]. In the second half of the twentieth century, when the question of the division of labor between man and machine and the role of machines in society was increasingly the subject of scientific debate, the concept of autonomy was transferred to industrial automation technologies [2]. In the course of this, the concept of autonomy 
changed from a right to a property. The underlying question was: "What capabilities must a system possess in order to act meaningfully without external interference?"

Following this guiding question, Sheridan and Verplank defined the level of automation (LoA) in 1978. The LoAs are applied to (industrial) automation systems which are defined as systems that work automatically [3], i. e., according to DIN 19233, they systematically execute stepwise predetermined decision rules or continuously execute processes over time according to defined relationships. The highest LoA was designated as "where the computer does [the] whole job if it decides it should be done, and if so tells the human, if it decides he should be told" [4].

This was defined as autonomy. Inspired by Sheridan and Verplank's approach of LoAs, several taxonomies were developed (e.g., [5-10]). In this context, autonomy is limited to the absence of human intervention. Intelligence or task entropy, i. e., the property of a task to be not pre-programmable, were seen as an orthogonal dimension $[4,11]$. The definition of autonomy in a broad sense originated from this mindset: the absence of (human) intervention.

But the definition of autonomy in the broad sense was later criticized as too simple and the usefulness of the LoAs was doubted (e. g., by the US Department of Defense) $[12,13]$. For example, Bradshaw et al. claimed in 2013 that autonomy is a complex, elusive, multidimensional property including a certain part of intelligence [14]. More people agreed on this view $[8,15]$ adding more attributes to the term of autonomy and therefore narrowing down the definition.

Aspects of artificial intelligence are now often included in the definitions: e. g., solving tasks without being programmed for it $[1,12]$, reaching goals without being told step by step how to accomplish them [8, 12, 16, 17], and the ability of making decisions despite incomplete information $[12,18]$.

Since the aspects of artificial intelligence are more often included within autonomy definitions, these aspects are also relevant for industrial autonomous systems. According to the survey on definitions of (artificial) intelligence by Legg and Hutter, three aspects cover the most popular properties of artificial intelligence.

The ability of interaction with the environment, the ability to succeed or profit with respect to goals and the ability to adapt to different environments [19].

A list of definitions of autonomy is given in Table 1, where characteristics are highlighted.

In addition to recognizing that autonomy contains the ability to make independent decisions, some of these definitions also imply uncertainties in the environment. Summing up the investigated literature, the authors of this contribution provide the following definition of an industrial autonomous system in the narrow sense:

An industrial autonomous system is a delimited technical system, which systematically and without external intervention, achieves its set objectives despite uncertain environmental conditions.

Note that, despite having predefined set objectives, an industrial autonomous system has the possibility to vary its instrumental goals [30] in order to achieve the overriding set objectives. However, they may not change the overriding objectives.

This definition captures the four characteristics that are more or less explicitly mentioned in most definitions and are therefore considered essential for an industrial autonomous system:

(1) systematic process execution

(2) adaptability to uncertain environmental conditions

Table 1: Various definitions of autonomy (SRCs = sources).

\begin{tabular}{ll}
\hline SRCs & Definition \\
\hline$[8,21-23]$ & $\begin{array}{l}\text { Autonomy is the ability to perform given tasks based on the system's perception without human intervention. } \\
{[24-26]}\end{array}$ \\
$\begin{array}{l}\text { Autonomy is an entity's ability of structuring its own actions and its environment without unwanted external } \\
\text { interference, i. e., it decides completely self-determined. }\end{array}$ \\
$\begin{array}{l}\text { Autonomy is the ability of an autonomous system to make decisions and justify its actions based on its sensor } \\
\text { measurements. The ultimate goal is to adapt to changes, which occur within the system itself, other systems it } \\
\text { interacts with, its operation environment, or in the given task. }\end{array}$ \\
$\begin{array}{l}\text { A system is autonomous if it is able to reach a predefined goal according to the current situation without recourse to } \\
\text { human control or detailed programming. Such systems can perceive their environment via sensors, proactively create } \\
\text { a plan of action according to the situation-related constraints and execute the planned actions safely and reliably via } \\
\text { actuators. } \\
\text { A system, which makes independent decisions and adapts to new conditions in order to achieve a predetermined } \\
\text { goal, acts autonomous. }\end{array}$ \\
\hline $12,16,28,29]$ &
\end{tabular}


Table 2: Characteristics of industrial autonomous systems.

\begin{tabular}{lll}
\hline Characteristic & SRCs & Definition \\
\hline $\begin{array}{l}\text { Systematic process } \\
\text { execution }\end{array}$ & {$[5,29]$} & Ability to execute modeled processes. \\
Adaptability & {$[31-35]$} & $\begin{array}{l}\text { Ability of a system to change its shape or behavior automatically to reach its goals with respect to } \\
\text { changes in its environment. } \\
\text { Ability of a system to manage the system's resources, without external interference, to make use } \\
\text { of them concerning reaching the predefined goals of the system, i. e., enabling the adaptability } \\
\text { property through administrative tasks and context-awareness. } \\
\text { Note that in the authors' opinion, self-governance and self-management have a similar meaning. } \\
\text { The goals and scope of the system are formulated precisely and in a holistic manner. This } \\
\text { includes, e. g.,, the time or state the system does not rely on human intervention, a set of services } \\
\text { and warranties. }\end{array}$ \\
\hline
\end{tabular}

(3) self-governance

(4) self-containedness of the system.

The characteristics are defined in Table 2. Moreover, sources supporting these characteristics are given.

\subsection{Distinction from classic industrial automation systems and intelligent industrial automation systems}

Based on the definition established in Section 3.1, a differentiation of industrial autonomous systems from classic industrial automation systems and intelligent industrial automation systems is discussed in the following subsection.

As industrial autonomous systems emerged from industrial automation systems and represent the highest LoA in most taxonomies, every industrial autonomous system is highly automated. However, highly automated systems are operated by humans. According to the LoAs, the need of intervention decreases with higher automation but only systems with the highest LoA, industrial autonomous systems, are completely independent from the help of the operator and other systems. Therefore, industrial automation systems focus on a fixed set of repeated tasks that can be preprogrammed rather than problems with unpredictable challenges [6]. The ability of (classic) industrial automation systems is to execute a pre-defined process systematically [40]. These systems are normally not capable to adapt to an uncertain environment without external intervention. A more detailed explanation can be found in $[40,41]$.

In short, industrial autonomous systems extend industrial automation systems by the intelligence to deal with uncertainty and the confidence to act without the explicit consent of a human operator.

The ability to solve problems without being especially programmed for them is generally achieved through intelligence. Therefore, any industrial autonomous system in the narrow sense is somehow an intelligent industrial automation system. However, there are intelligent industrial automation systems that are not autonomous. Within the literature, there is no consent about the term intelligence [37]. Similarities are listed in [19, 20, 37]. For our focus, we choose the definition of Legg and Hutter: "Intelligence measures an agent's ability to achieve goals in a wide range of environments" [19]. According to this definition, and consistent with the recent investigation of Monett and Winkler [20], one essential characteristic of an intelligent system is adaptability. This adaptability may be achieved either with or without the intervention of a human operator or knowledge engineer. An intelligent industrial automation system is only called an industrial autonomous system if no human intervention is required. Two further characteristics are used to distinguish intelligent industrial automation systems and industrial autonomous systems: self-governance and self-containedness. Both characteristics are discussed in more detail in Section 4. Only if a system possesses these characteristics, the intelligent industrial automation system is considered as an industrial autonomous system. Therefore, currently there are many intelligent industrial automation systems that are not autonomous:

"It has been argued that, currently, many kinds of intelligent artifacts-autonomous agents, systems, and robots-are not truly autonomous, capable of dealing with complex, uncertain, and unpredictable environments independently, that is, truly autonomously" [28]. 
a)

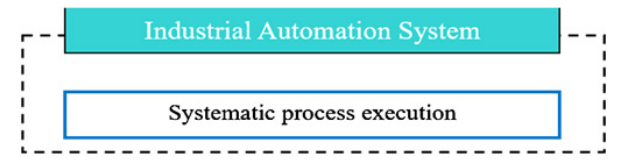

b)

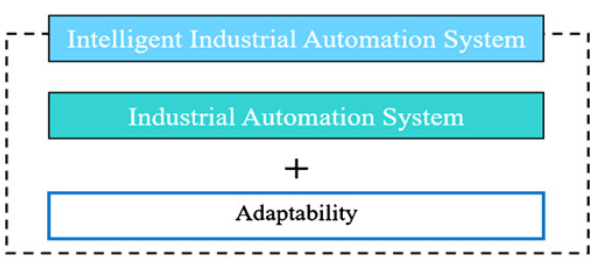

c)

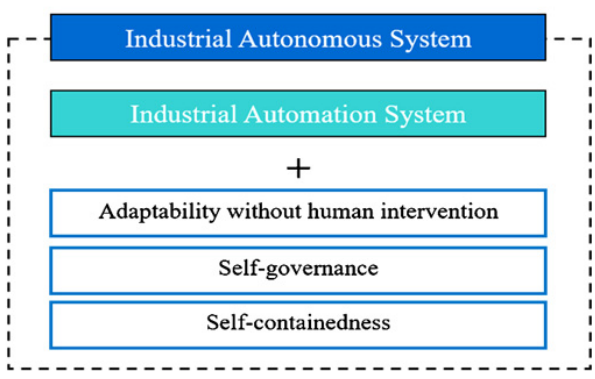

Figure 1: Differences between (classic) industrial automation systems, intelligent industrial automation systems and industrial autonomous systems.

Note that this distinction highly depends on the definition of autonomy. For example, having in mind the definition of autonomy in the broad sense, Hrabia et al. distinguish automation systems, autonomous systems and intelligent systems differently:

\begin{abstract}
"So we state that an automation system is autonomous but is usually not an intelligent system. Another important subcategory of autonomous systems are autonomic systems [...], whose focus is self-management, with the goal of configuring, healing, optimizing, and protecting itself in order to recover from failures or optimize for changed conditions.” [1].
\end{abstract}

The essence of the differences between (classic) industrial automation systems (a), intelligent industrial automation systems (b), and industrial autonomous systems (c) is summarized in Fig. 1.

\section{Abilities of industrial autonomous systems}

The intent of using autonomous systems is mainly (a) to tame the complexity of a system of systems by using autonomous components [42], (b) to make the system robust concerning fundamental uncertainties [12], (c) to reduce the workload of human operators [43] or (d) to operate in hostile environments [36] where teleoperation is not feasi-

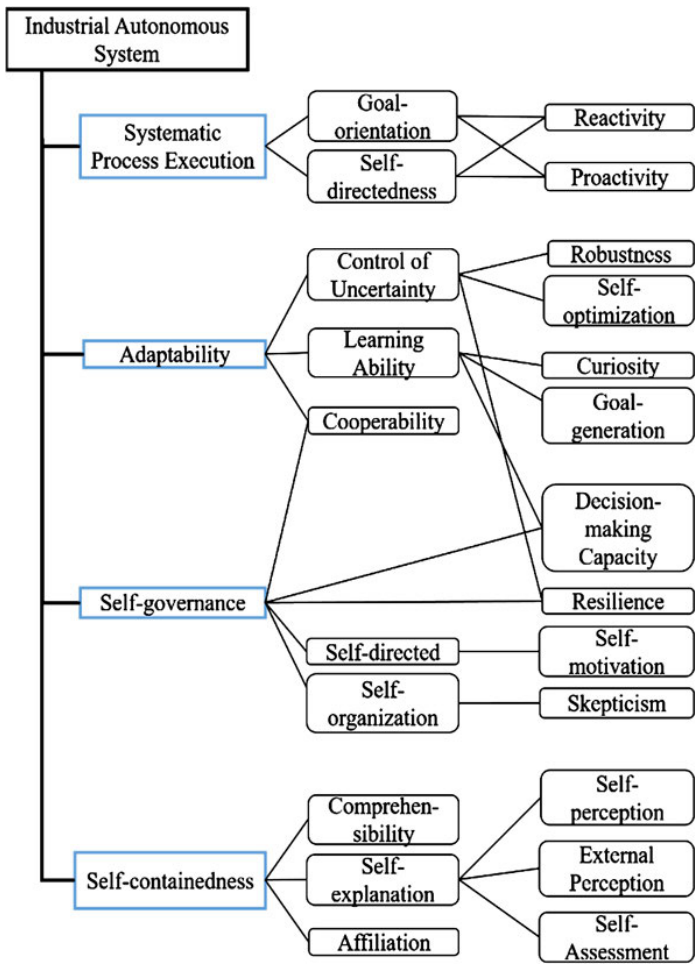

Figure 2: Structure of characteristics and abilities of industrial autonomous systems.

ble. As the intent of using autonomy and the understanding of autonomy vary (cf. Section 3), the abilities ascribed to industrial autonomous systems vary as well. Nevertheless, the abilities may be linked to the found characteristics and may be structured. The approach of structuring the characteristics and abilities is visualized in Fig. 2 .

The industrial autonomous system is divided into the characteristics (rectangles) systematic process execution, adaptability, self-governance, self-containedness and the corresponding abilities (rounded rectangles) as denoted in Fig. 2. The precise definitions of the abilities and the references to the literature are listed in Table 3.

Referring to the Cambridge Dictionary, an ability is "the mental or physical power or skill needed to do something”. Transferring this definition to industrial autonomous systems, an ability describes the power or skill of the system to do something.

The abilities are structured into two layers where the sub-abilities contribute to the main abilities. In some cases sub-abilities contribute to several main abilities, e.g., reactivity contributes to both, goal-orientation and selfdirectedness. The abilities that are necessary to give the system the essential characteristics of an autonomous system differ from case to case. 
Table 3: Abilities of industrial autonomous systems.

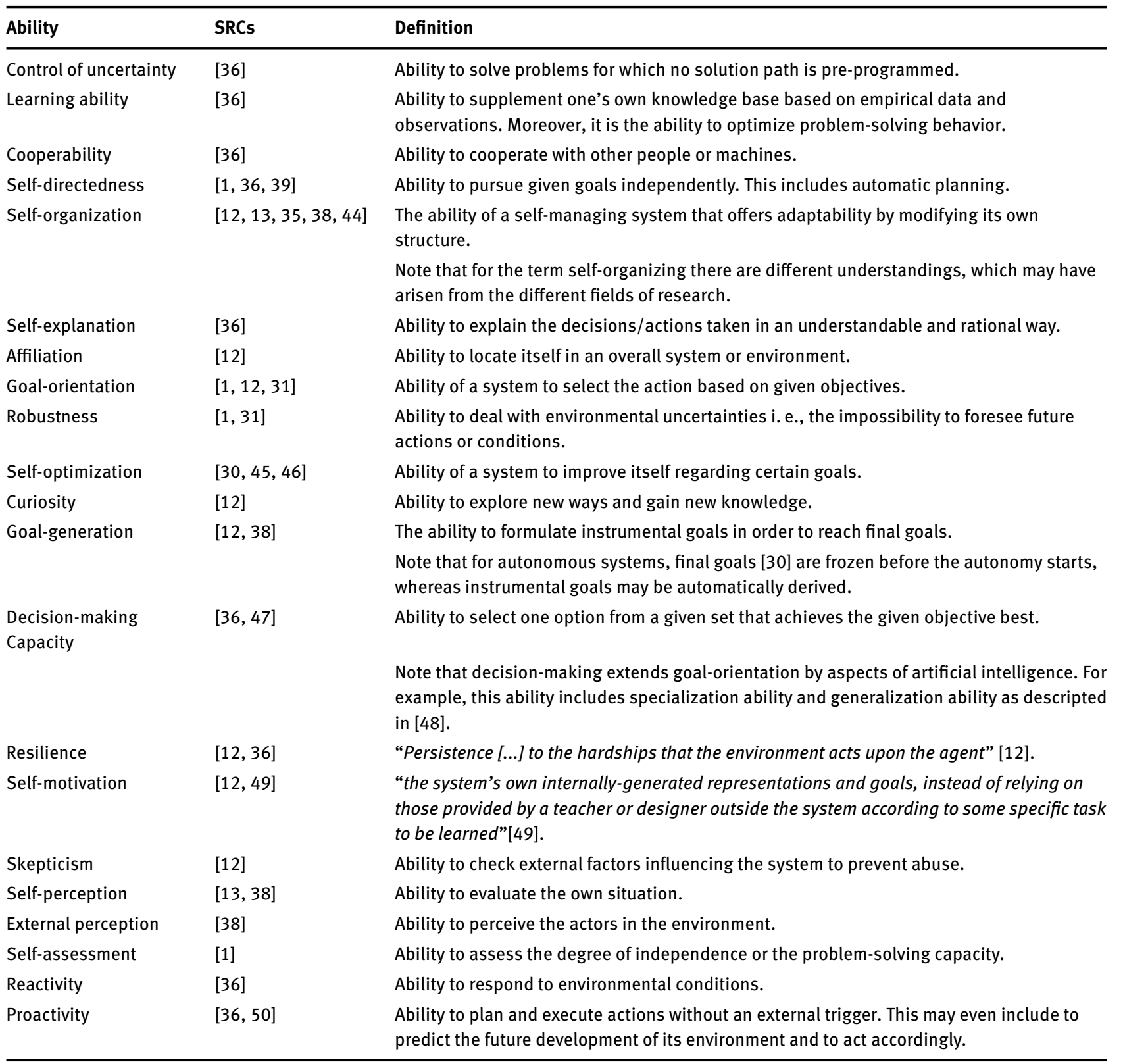

5 Application of the characteristics on industrial autonomous systems

To illustrate the characteristics and abilities of an industrial autonomous system based on industrial use cases, this paper gives a detailed description of three realized use cases applied in industry: (1) autonomous automated guided vehicles in a flexible manufacturing system, (2) autonomous power grids, and (3) autonomous roadside infrastructure.
In order to realize a use case for an industrial autonomous system, the Institute of Industrial Automation and Software Engineering at the University of Stuttgart in cooperation with industrial partners, KUKA, TRUMPF and Siemens has built a flexible manufacturing system in the ARENA2036, Active Research Environment for the Next Generation of Automotive, see Fig. 3. In [51] the authors give a detailed description of the flexible manufacturing system structure.

The flexible manufacturing system consists of four automated systems with decentralized control (welding machine, a mobile robot (KMR iiwa) as an autonomous au- 


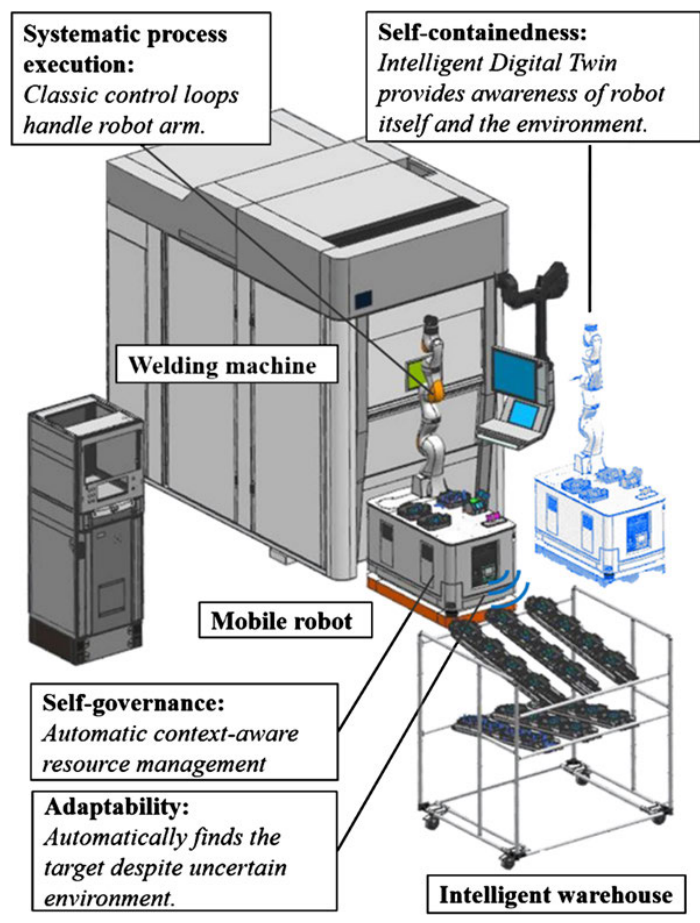

Figure 3: 3D-CAD model of the flexible manufacturing system in the ARENA2036.

tomated guided vehicle, an intelligent warehouse, and a control cabinet as a head control system), which produce a model car from four metal sheet parts. The automated systems are not arranged in a fixed, conventional line system. Instead, the mobile robot connects them as a driverless transport vehicle. The intelligent warehouse is used as a warehouse for the pre-produced sheet metal parts, which are made available to the mobile robot. The sheet metal parts are grouped together in different workpiece carriers for better handling. The position of the intelligent warehouse is flexible due to its movable structure and the robot can detect its position by communication via WLAN and using detection sensors, integrated on the robot. Furthermore, the mobile robot can automatically recognize and access the necessary metal sheets for assembling various model car variants in the intelligent warehouse using an integrated camera.

The mobile robot is an example of an industrial autonomous system because it exhibits the four characteristics of autonomy. The property of the mobile robot to respond to the environmental conditions with classic control loops corresponds to the characteristic of systematic process execution. Due to integrated sensors on its system and developed data analysis algorithms on its control system, it has the ability to detect a new position of the intelligent warehouse. This demonstrates the character- istic adaptability to uncertain environmental conditions. According to the evaluation algorithms integrated on the robot to evaluate the gripping, the robot has the ability to evaluate its own situation. Based on the robot's situation the resources like battery level are managed providing the self-organization ability. Managing that the right part gets to the welding machine in time uses the abilities: cooperativity, self-directedness and decision-making. Therefore, the robot has the characteristic of self-governance. Having an Intelligent Digital Twin as proposed in [52], the robot has a detailed view on itself, namely, it knows about its interfaces and the services it provides. Moreover, knowledge about its surrounding systems and the way to communicate with them is given by the co-simulation interface. Thus, the self-containedness characteristic is achieved.

The second use case considers distributed autonomous power electric micro-grids [53]. This kind of system aims to intelligently manage customer-owned, loosely coupled, distributed energy resources. In case of a blackout, the system gradually stabilizes and restarts the electricity net. Moreover, it automatically balances the electrical energy based on a bulletin board market place. This system is an industrial autonomous system, because the four criteria are met. The described system systematically monitors the demand and production of the electricity and balances it by the control strategy of the underlying electricity resources. Therefore, it displays the characteristic of systematic process execution. Moreover, the agent-based approach adapts pricing and balances the load without human intervention. This concept manages the environmental uncertainties about the needs and production of electricity and therefore meets the characteristic of adaptability. The energy resources are managed by the agent system itself managing dynamic switch-onswitch-off scenarios. The abilities of resilience and selfoptimization are used to handle these scenarios and therefore implement the characteristic of self-governance. Finally, the scope of this application is delimited. The provided services are load balancing and pricing, the system is aware of its components and its interfaces reflecting self-perception. External perception is demonstrated by monitoring of the coupled grid. Therefore, the characteristic of self-containedness is met.

The third use case considers an autonomous roadside infrastructure. This infrastructure enables highly automated driving functions and supports the logistics. The scope of this infrastructure is to perform automatic sensor calibration [54], provide accurate traffic information and automatically detect and exclude misbehaving infrastructure elements [55]. 
In this case, the characteristic of systematic process execution refers to the process loop of acquiring the sensor data, processing them and providing them to the connected road users. The challenge of providing constantly high-quality information despite uncertain environmental conditions like fog, different light conditions, etc., is met through self-calibration algorithm based on subjective logic. This algorithm provides the learning ability and selfoptimization, thus realizing the characteristic of adaptability. Moreover, the system may be considered self-governing as it automatically manages its resources by excluding misbehaving elements and fusing the information from different parts of the infrastructure. This behavior is based on the abilities of resilience and skepticism. Because the scope of this infrastructure is well delimited, the characteristic of self-containedness is met. The abilities of selfexplanation and affiliation are provided by the communication protocol identifying the infrastructure, its parameters (e. g., quality information and trust level) and the relationship to the road user. Note that in contrast to the infrastructure, most vehicles are considered intelligent automated systems but not autonomous ones. This is due to the fact that the scope of the vehicles lack self-containedness.

\section{Conclusion and outlook}

The term industrial autonomous system has not clearly been defined within the literature so far. To address this confusion, a literature review was conducted in order to identify the common essential characteristics of industrial autonomous systems.

Starting with an investigation of the historical development of the term autonomy, different definitions were compared and finally a concluding concept of autonomy was derived for the application domain of industrial automation systems. Based on this definition, four essential characteristics of industrial autonomous systems were identified: systematic process execution, adaptability, self-governance and self-containedness. Subsequently, industrial autonomous systems were distinguished from classic industrial automation systems and intelligent industrial automation systems. Furthermore, the abilities which, according to the literature, can be possessed by industrial autonomous systems, were examined and set in relation to the four mentioned characteristics. In order to examine the relations between the characteristics and abilities by means of industrial examples, three use case scenarios of industrial autonomous systems were described in detail. It was shown how systems can be clas- sified as industrial autonomous systems based on the derived four characteristics.

In this paper, the essential characteristics and their implementation by means of abilities were shown. The mentioned aspects are particularly focused on the engineering phase. Based on this, it remains to be investigated how the mentioned characteristics can be safeguarded within the operational phase. Another open research question is how an appropriate reconfiguration management of industrial autonomous systems during operation can be applied in order to enable the system to react to dynamic changes in requirements. Therefore, further research is required within the fields of safeguarding and self-management of industrial autonomous systems.

\section{References}

1. C.-E. Hrabia, N. Masuch and S. Albayrak, "A Metrics Framework for Quantifying Autonomy in Complex Systems," in Lecture notes in artificial intelligence, 0302-9743, vol. 9433, Multiagent system technologies: 13th German Conference, MATES 2015, Cottbus, Germany, September 28-30, 2015.

2. M. Vagia, A. A. Transeth and S. A. Fjerdingen, “A literature review on the levels of automation during the years. What are the different taxonomies that have been proposed?," Applied ergonomics, vol. 53, pp.190-202, 2016.

3. What is Automation?- ISA. [Online]. Available: https://www.isa. org/about-isa/what-is-automation/ (accessed: Mar. 20 2020).

4. T. B. Sheridan and W. L. Verplank, "Human and computer control of undersea teleoperators," Massachusetts Inst of Tech Cambridge Man-Machine Systems Lab, 1978.

5. T. Gamer, M. Hoernicke, B. Kloepper, R. Bauer and A. J. Isaksson, "The Autonomous Industrial Plant-Future of Process Engineering, Operations and Maintenance," IFAC-PapersOnLine, vol. 52, no. 1, pp. 454-460, 2019.

6. R. Parasuraman and V. Riley, "Humans and Automation: Use, Misuse, Disuse, Abuse," Hum Factors, vol. 39, no. 2, pp. 230-253, 1997.

7. D. B. Kaber and M. R. Endsley, "The effects of level of automation and adaptive automation on human performance, situation awareness and workload in a dynamic control task," Theoretical Issues in Ergonomics Science, vol. 5, no. 2, pp. 113-153, 2004.

8. J. M. Beer, A. D. Fisk and W. A. Rogers, "Toward a framework for levels of robot autonomy in human-robot interaction," Journal of human-robot interaction, vol. 3, no. 2, pp. 74-99, 2014.

9. J. O. Kephart and D. M. Chess, "The vision of autonomic computing," Computer, vol. 36, no. 1, pp. 41-50, 2003.

10. W. Damm and R. Kalmar, “Autonome Systeme," Informatik Spektrum, vol. 40, no. 5, pp. 400-408, 2017.

11. V. Riley, "A General Model of Mixed-Initiative Human-Machine Systems," Proceedings of the Human Factors Society Annual Meeting, vol. 33, no. 2, pp. 124-128, 1989.

12. H. A. Abbass, J. Scholz and D. J. Reid, Foundations of trusted autonomy. Cham, Switzerland: Springer Open, 2018. 
13. "Defense Science Board Task Force Report: The Role of Autonomy in DoD Systems," DEFENSE SCIENCE BOARD WASHINGTON DC. [Online]. Available: https://apps.dtic.mil/ $\mathrm{dtic} / \mathrm{tr} /$ fulltext/u2/a566864.pdf.

14. J. M. Bradshaw, R. R. Hoffman, M. Johnson and D. D. Woods, "The Seven Deadly Myths of "Autonomous Systems"," IEEE Intell. Syst., vol. 28, no. 3, pp. 54-61, 2013.

15. J. Connelly, W. S. Hong, R. B. Mahoney Jr and D. A. Sparrow, "Challenges in autonomous system development," PERFORMANCEMETRICS, p. 220, 2006.

16. D. P. Watson and D. H. Scheidt, "Autonomous systems," Johns Hopkins APL technical digest, vol. 26, no. 4, pp. 368-376, 2005.

17. R. Alami, R. Chatila, S. Fleury, M. Ghallab and F. Ingrand, "An Architecture for Autonomy," The International Journal of Robotics Research, vol. 17, no. 4, pp. 315-337, 1998.

18. A. Aniculaesei, J. Grieser, A. Rausch, K. Rehfeldt and T. Warnecke, "Towards a holistic software systems engineering approach for dependable autonomous systems," in 2018 ACM/IEEE 1st International Workshop on Software Engineering for Al in Autonomous Systems: SEFAIAS 2018: 28 May 2018, Gothenburg, Sweden: proceedings, Gothenburg, Sweden, 2018, pp. 23-30.

19. S. Legg and M. Hutter, "A Collection of Definitions of Intelligence," Frontiers in Artificial Intelligence and Applications, Vol. 157 ([Online]. Available: https://arxiv.org/ pdf/0706.3639).

20. D. Monett and C. Winkler, "Using Al to Understand Intelligence: The Search for a Catalog of Intelligence Capabilities," [Online]. Available: ceur-ws.org/Vol-2521/paper-05.pdf.

21. J. Albus and P. J. Antsaklis, "Panel discussion: Autonomy in engineering systems: What is it and why is it important? Setting the stage: Some autonomous thoughts on autonomy," in Proceedings of the 1998 IEEE International Symposium on Intelligent Control (ISIC) held jointly with IEEE International Symposium on Computational Intelligence in Robotics and Automation (CIRA) Intell, 1998, pp. 520-521.

22. J. Papp, D. Tokody and F. Flammini, "From traditional manufacturing and automation systems to holonic intelligent systems," Procedia Manufacturing, vol. 22, pp. 931-935, 2018.

23. E. Prestes et al., "Towards a core ontology for robotics and automation," Robotics and Autonomous Systems, vol. 61, no. 11, pp. 1193-1204, 2013.

24. M. Fisher, L. Dennis and M. Webster, "Verifying autonomous systems," Commun. ACM, vol. 56, no. 9, p. 84, 2013.

25. S. A. Redfield and M. L. Seto, "Verification Challenges for Autonomous Systems," in Autonomy and Artificial Intelligence: A Threat or Savior?: Springer, 2017, pp. 103-127.

26. N. Gronau and H. Theuer, "Determination of the Optimal Degree of Autonomy in a Cyber-Physical Production System," Procedia CIRP, vol. 57, pp. 110-115, 2016.

27. H. Kagermann, N. Gaus, J. Hauck, J. Beyerer, W. Wahlster and H. Brackemann, "Autonome Systeme-Chancen und Risiken für Wirtschaft, Wissenschaft und Gesellschaft. Fachforum Autonome Systeme im Hightech-Forum," Abschlussbericht-Langversion. Berlin, 2017.

28. R. Sun, "Intrinsic Motivation for Truly Autonomous Agents," in Studies in systems, decision and control, 2198-4182, volume 117, Foundations of trusted autonomy, H. A. Abbass, J. Scholz and D. J. Reid, Eds., Cham, Switzerland: Springer Open, 2018, pp. 273-292.

29. M. A. Ramos, C. A. Thieme, I. B. Utne and A. Mosleh, Proceedings of the First International Workshop on Autonomous Systems Safety: Norwegian University of Science and Technology.

30. S. Armstrong, "General Purpose Intelligence: Arguing the Orthogonality Thesis," Analysis and Metaphysics, no. 12, pp. 68-84, 2013. [Online]. Available: https://www.ceeol.com/ content-files/document-133405.pdf.

31. C. Janiesch, M. Fischer, A. Winkelmann and V. Nentwich, "Specifying autonomy in the Internet of Things: the autonomy model and notation," Inf Syst E-Bus Manage, vol. 17, no. 1, pp. 159-194, 2019.

32. C. Janiesch and V. Nentwich, "Autonomie im Internet der Dinge: Anforderungen an die Gestaltung autonomer Agenten in Cyber-physischen Systemen," 2017.

33. A. Musil, J. Musil, D. Weyns, T. Bures, H. Muccini and M. Sharaf, "Patterns for Self-Adaptation in Cyber-Physical Systems," in Multi-Disciplinary Engineering for Cyber-Physical Production Systems, S. Biffl, A. Lüder and D. Gerhard, Eds., Cham: Springer International Publishing, 2017, pp. 331-368.

34. D. Weyns, "Software Engineering of Self-adaptive Systems," in Handbook of Software Engineering: Springer, 2019, pp. 399-443.

35. J. Sudeikat, L. Braubach, A. Pokahr, W. Renz and W. Lamersdorf, "Systematically engineering self-organizing systems: The SodekoVS approach," Electronic Communications of the EASST, vol. 17, 2009.

36. W. Wahlster, "Künstliche Intelligenz als Grundlage autonomer Systeme," Informatik Spektrum, vol. 40, no. 5, pp. 409-418, 2017.

37. J.P. Gunderson and L. F. Gunderson, "Intelligence= autonomy= capability," Performance Metrics for Intelligent Systems, PERMIS, 2004.

38. R. Clothier, B. Williams and T. Perez, Autonomy from a Safety Certification Perspective, 2019.

39. J. M. Bradshaw, P. J. Feltovich, H. Jung, S. Kulkarni, W. Taysom and A. Uszok, "Dimensions of Adjustable Autonomy and Mixed-Initiative Interaction," in: Lecture notes in computer science, 0302-9743, 2969. Lecture notes in artificial intelligence, Agents and computational autonomy: Potential, risks, and solutions / Matthias Nickles, Michael Rovatsos, Gerhard Weiss (eds.), M. Nickles, M. Rovatsos and G. Weiss, Eds., Berlin, London: Springer, 2004, pp. 17-39.

40. S. MahmoudZadeh, D. M. W. Powers and R. B. Zadeh, "Introduction to autonomy and applications," in Autonomy and Unmanned Vehicles: Springer, 2019, pp.1-15.

41. S. J. Russell and P. Norvig, Artificial intelligence: $A$ modern approach / Stuart J. Russell and Peter Norvig; contributing writers, Ernest Davis [and seven others]. Boston: Pearson, 2016.

42. P. Zhou et al., "A Comprehensive Technological Survey on the Dependable Self-Management CPS: From Self-Adaptive Architecture to Self-Management Strategies," Sensors (Basel, Switzerland), vol. 19, no. 5, 2019.

43. C. Klein, R. Schmid, C. Leuxner, W. Sitou and B. Spanfelner, "A Survey of Context Adaptation in Autonomic Computing," in Fourth International Conference on Autonomic and Autonomous Systems (ICAS'08), Gosier, Guadeloupe, Mar. 2008 - Mar. 2008, pp. 106-111. 
44. M. C. Jaeger, M. Werner, G. Mühl, H.-U. Heiß, U. Laude and C. Ruge, "Autonomie in IT-Systemen. Ein Konzeptionelles Modell," PIK-Praxis der Informationsverarbeitung und Kommunikation, vol. 31, no. 1, pp. 4-11, 2008.

45. J. O. Kephart, D. M. Chess, J. O. Kephart and D. M. Chess, "The vision of autonomic computing," Computer, vol. 36, no.1, pp. 41-50, 2003.

46. H. Psaier and S. Dustdar, "A survey on self-healing systems: approaches and systems," Computing, vol. 91, no. 1, pp. 43-73, 2011.

47. H.-M. Huang, "Autonomy Levels For Unmanned Systems (ALFUS) framework, volume I," Gaithersburg, MD, 2008.

48. Michael Weyrich et al., "Evaluation Model for Assessment of Cyber-Physical Production Systems," in Industrial Internet of Things: Springer, Cham, 2017, pp.169-199. [Online]. Available: https://link.springer.com/chapter/10.1007/978-3-319-425597_7.

49. An emergent framework for self-motivation in developmental robotics, 2004. [Online]. Available: https://repository. brynmawr.edu $/$ cgi $/$ viewcontent.cgi?article $=1045 \&$ context $=$ compsci_pubs.

50. VDI, VDI/VDE 2653 Blatt 1 - Agentensysteme in der Automatisierungstechnik - Grundlagen. [Online]. Available: https://www.vdi.de/richtlinien/details/vdivde-2653-blatt-1agentensysteme-in-der-automatisierungstechnik-grundlagen (accessed: Nov. 20 2020).

51. B. A. Talkhestani, D. Braun, W. Schloegl and M. Weyrich, "Qualitative and quantitative evaluation of reconfiguring an automation system using Digital Twin," Procedia CIRP, vol. 93, pp. 268-273, 2020.

52. B. Ashtari Talkhestani et al., "An architecture of an Intelligent Digital Twin in a Cyber-Physical Production System," at Automatisierungstechnik, vol. 67, no. 9, pp. 762-782, 2019.

53. S. Rahman, M. Pipattanasomporn and Y. Teklu, "Intelligent Distributed Autonomous Power Systems (IDAPS)," in 2007 IEEE Power Engineering Society General Meeting, Tampa, FL 24-28 June, 2007, Tampa, FL, USA, 2007, pp.1-8.

54. J. Müller, M. Herrmann, J. Strohbeck, V. Belagiannis and M. Buchholz, "LACl: Low-effort Automatic Calibration of Infrastructure Sensors,” Nov. 2019. [Online]. Available: http://arxiv.org/pdf/1911.01711v1.

55. J. Müller, T. Meuser, R. Steinmetz and M. Buchholz, “A Trust Management and Misbehaviour Detection Mechanism for Multi-Agent Systems and its Application to Intelligent Transportation Systems," May. 2019. [Online]. Available: http://arxiv.org/pdf/1905.09065v1.

\section{Bionotes}

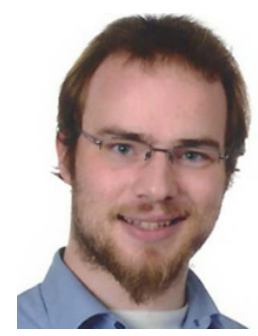

\section{Manuel Müller}

Institute of Industrial Automation and Software Engineering, University of Stuttgart, Stuttgart, Germany manuel.mueller@ias.uni-stuttgart.de

Manuel Müller, M. Sc. is a research assistant at the Institute of Industrial Automation and Software Engineering at the University of Stuttgart. His research focusses on safeguarding industrial autonomous systems during operation.

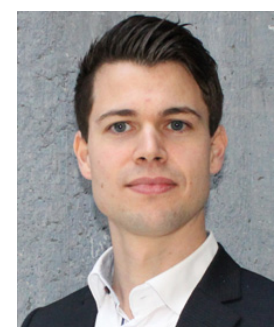

\section{Timo Müller}

Institute of Industrial Automation and Software Engineering, University of Stuttgart, Stuttgart, Germany timo.mueller@ias.uni-stuttgart.de

Timo Müller, M. Sc. is a research assistant at the Institute of Industrial Automation and Software Engineering at the University of Stuttgart. His research focusses on the reconfiguration of cyberphysical production systems.

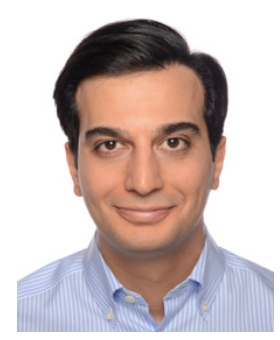

\section{Behrang Ashtari Talkhestani} Institute of Industrial Automation and Software Engineering, University of Stuttgart, Stuttgart, Germany behrang.ashtari@ias.uni-stuttgart.de

Dr.-Ing. Behrang Ashtari Talkhestani was a research assistant at the Institute of Industrial Automation and Software Engineering at the University of Stuttgart from 2016 to 2020. His research has focussed on the synchronization of the digital twin with a real production system. 


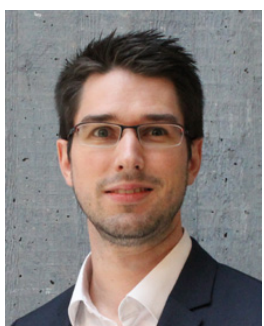

\section{Philipp Marks}

Institute of Industrial Automation and Software Engineering, University of Stuttgart, Stuttgart, Germany philipp.marks@ias.uni-stuttgart.de

Dr.-Ing. Philipp Marks was a research assistant at the Institute of Industrial Automation and Software Engineering at the University of Stuttgart from 2015 to 2020 . His research has focussed on software assistance for the modernization of automation systems.

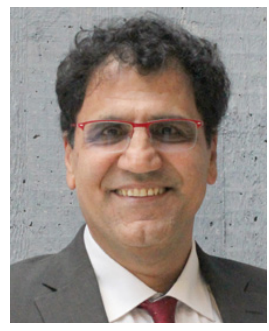

\section{Nasser Jazdi}

Institute of Industrial Automation and

Software Engineering, University of

Stuttgart, Stuttgart, Germany

nasser.jazdi@ias.uni-stuttgart.de

Dr.-Ing. Nasser Jazdi is the deputy head of the Institute of Industrial Automation and Software Engineering at the University of Stuttgart. His research focusses on the Internet of Thinfs as well as learning ability, reliability, safety and artificial intelligence in industrial automation.

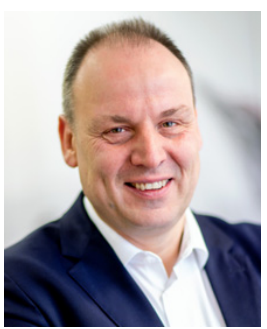

Michael Weyrich

Institute of Industrial Automation and Software Engineering, University of Stuttgart, Stuttgart, Germany michael.weyrich@ias.uni-stuttgart.de

Prof. Dr.-Ing. Dr. h. c. Michael Weyrich teaches at the University of Stuttgart and is head of the Institute of Industrial Automation and Software Engineering. His research focuses on intelligent automation systems, complexity control of cyber-physical systems and validation and verifcation of automation systems. 